\title{
Philosophiques
}

\section{Livres reçus (printemps 1999)}

Volume 26, numéro 1, printemps 1999

URI : https://id.erudit.org/iderudit/004949ar

DOI : https://doi.org/10.7202/004949ar

Aller au sommaire du numéro

Éditeur(s)

Société de philosophie du Québec

ISSN

0316-2923 (imprimé)

1492-1391 (numérique)

Découvrir la revue

Citer ce document

(1999). Livres reçus (printemps 1999). Philosophiques, 26(1), 169-171.

https://doi.org/10.7202/004949ar d'utilisation que vous pouvez consulter en ligne.

https://apropos.erudit.org/fr/usagers/politique-dutilisation/ 


\section{Livres reçus (printemps 1999)}

Arnold, Matthieu, Les femmes dans la correspondance de Luther, Paris, PUF («Études d'histoire et de philosophie religieuse »), $126 \mathrm{p}$.

Benoist, Jocelyn, Robert Brisart et Jacques English, Liminaires phénoménologiques. Recherches sur le développement de la théorie de la signification de Husserl, Bruxelles, Publications des Facultés universitaires Saint-Louis, 1998, $281 \mathrm{p}$.

Bertrand, Pierre, Le cour silencieux des choses. Essai sur l'écriture comme exercice de survie, Montréal, Liber, 1999, 169 p.

Boudon, Raymond, Le sens des valeurs, Paris, PUF (" Quadrige »), 1999, $397 \mathrm{p}$.

Castel, Pierre-Henri, Introduction à L'interprétation du rêve de Freud, Paris, PUF ( "Les grands livres de la philosophie »), 1998, 398 p.

Combes, Muriel, Simondon. Individu et collectivité, Paris, PUF ( "Philosophies»), 1999, $133 \mathrm{p}$.

Conche, Marcel, L'aléatoire, Paris, PUF ( «Perspectives critiques »), 1999, $239 \mathrm{p}$.

Courtois, Jean-Patrice, Inflexions de la rationalité dans "L'Esprit des lois», Paris, PUF ( «Écrivains »), 1999, 321 p.

Dillens, A.-M. et al., Questions au libéralisme, Bruxelles, Publications des Facultés universitaires Saint-Louis, 1999.

Druet, François-Xavier et Étienne Ganty (éds), Rendre justice au droit. En lisant Le Juste de Paul Ricœur, Namur, Presses universitaires de Namur, 1999, 320 p.

Fichte, J.G., Fondement du droit naturel selon les principes de la doctrine de la science, Présentation, trad. et notes par A. Renaut, Paris, PUF ( "Quadrige »), 1998, 418 p.

Fischbach, Franck, Fichte et Hegel. La reconnaissance, Paris, PUF («Philosophies»), 1999, 133 p.

Gauthier-Muzellec, Marie-Hélène, Aristote et la juste mesure, Paris, PUF ( «Philosophies»), 1998, 133 p.

Gilson, Étienne, La philosophie au Moyen-Âge. Des origines patristiques à la fin $d u X I V^{e}$ siècle, Paris, Payot, 1999, $782 \mathrm{p}$.

Grondin, Jean, Hans-Georg Gadamer. Eine Biographie, Tübingen, Mohr Siebeck, 1999, $437 \mathrm{p}$.

Guineret, Hervé, Clausewitz et la guerre, Paris, PUF ( Philosophies »), 1999, $131 \mathrm{p}$.

Haakonssen, Knud, L'art du législateur. La jurisprudence naturelle de David Hume et d'Adam Smith, trad. de l'anglais par F. Kearns, Paris, PUF ( Léviathan »), 1998, 278 p.

Hegel, G.W.F., Principes de la philosophie $d u$ droit, texte intégral, accompagné d'extraits des cours de Hegel, présenté, révisé, traduit et 
annoté par J.-F. Kervégan, Paris, PUF ( « Fondements de la politique »), 1998, $478 \mathrm{p}$.

Jacques, Daniel, Nationalité et modernité, Montréal, Boréal, 1998, 269 p.

Kerszberg, Pierre, Kant et la nature. La nature à l'épreuve de la critique,

Paris, Les Belles Lettres ( "L'âne d'or »), 1999, 384 p.

Lamy, Bernard, La rhétorique ou l'art de parler, éd. critique établie par

B. Timmermans, Paris, PUF («L'interrogation philosophique»), 1998, 598 p.

Marion, Mathieu, Wittgenstein, Finitism, and the Foundations of Mathematics, Oxford, Clarendon Press («Oxford Philosophical Monographs »), 1998, 260 p.

Michaud, Yves, Locke, Paris, PUF ( Q Quadrige »), 1998, 292 p.

Mill, John Stuart, L'utilitarisme et Essai sur Bentham, Paris, PUF ( Q Quadrige »), 1998, $253 \mathrm{p}$.

Naya, Emmanuel, Rabelais. Une anthropologie humaniste des passions, Paris, PUF ( "Philosophies »), 1998, 133 p.

Nicole, Pierre, Essais de morale, essais choisis, introduits et annotés par

L. Thirouin, Paris, PUF ( « Philosophie morale »), 1999, 441 p.

Ogien, Ruwen (dir.), Le réalisme moral, Paris, Presses universitaires de France («Philosophie morale»), 1999, $571 \mathrm{p}$.

Pietra, Régine (dir.), Esthétique: des gô̂ts et des couleurs..., Grenoble, Recherches sur la philosophie et le langage ( $C$ Cahier n $20 »), 1998$, 296 p.

Rosen, Stanley, Metaphysics in Ordinary Language, New Haven/London, Yale University Press, 1999, 290 p.

Smarandache, Florentin, Neutrosophy. Neutrosophic Probability, Set, and Logic, Rehoboth, American Research Press, 1998, 105 p.

Spitz, Jean-Fabien, Bodin et la souveraineté, Paris, PUF ( Philosophies »), 1998, 133 p.

Vaysse, Jean-Marie, Hegel. Temps et histoire, Paris, PUF ( Philosophies »), 1998, 133 p.

Veca, Salvatore, Éthique et politique, Paris, PUF ( Philosophie morale »), 1999, $234 \mathrm{p}$.

Wittgenstein, Ludwig, Leçons sur la liberté de la volonté, suivi de Essai sur le libre jeu de la volonté, par Antonia Soulez, Paris, Presses universitaires de France ("Épiméthée »), 1998, 355 p. 
Les personnes intéressées à faire un compte rendu de l'un ou l'autre des ouvrages qui apparaissent dans cette liste sont priées de s'adresser à :

Daniel Dumouchel

Université de Montréal

Département de philosophie

C.P. 6128 Succ. Centre-ville

Montréal, Québec, H3C 3J7

tél: (514) 343-6484

télec: (514) 343-7899

Courriel : dumouchd@ere.umontreal.ca 